\title{
Damage Detection for Curved Surfaces Using Advanced Piezo Impedance Transducers
}

\author{
Ashwini U. Rankhamb, Suraj N. Khante* \\ Applied Mechanics Department, Government College of Engineering Amravati, Amravati, India \\ Email: ashwini.rankhamb26@gmail.com, ${ }^{*}$ snkhante@yahoo.com
}

How to cite this paper: Rankhamb, A.U. and Khante, S.N. (2016) Damage Detection for Curved Surfaces Using Advanced Piezo Impedance Transducers. Open Journal or Civil Engineering, 6, 722-736. http://dx.doi.org/10.4236/ojce.2016.65058

Received: October 5, 2016

Accepted: November 8, 2016

Published: November 11, 2016

Copyright $\odot 2016$ by authors and Scientific Research Publishing Inc. This work is licensed under the Creative Commons Attribution International License (CC BY 4.0).

http://creativecommons.org/licenses/by/4.0/ (c) (i) Open Access

\begin{abstract}
In recent years, it is necessary to monitor every civil and mechanical structure for the safety of human life and property. By using PZT, monitoring of structures is possible with some limitations such as direct attachment to the host structure, structure subjected to impact from external forces, inaccessible structure, high temperature locations, and structures with complex geometry and curved surfaces. To overcome these limitations, a new technique is employed for structural health monitoring. Using the advanced technique, transducer is prepared by attaching PZT with metal connectors which is in turn attached to the monitored structure. This paper demonstrates experimental study on mild steel pipes. Different aspects of SHM are studied. The proposed technique effectively detects locations of damages and severity of damages of pipe specimen. The technique is also employed to study effect of temperature variation along with detecting progressive damage of pipe specimen when it is subjected to steady constant high temperature. This technique is applicable to high temperature locations as the temperature of PZT maintained below its Curie temperature by introducing metal connector between structure and PZT patch. For the quantification of damages, the RMSD index formula is used.
\end{abstract}

\section{Keywords}

Advanced PZT, Progressive Damage, Metal Connector, Structural Health Monitoring, Curie Temperature

\section{Introduction}

\subsection{General}

A pipeline is the important part of our civil infrastructure of every country. It experiences damages during its service life, for e.g. internal corrosion, bursting due to internal forces, cracks; leakages due to improper joints, etc. If it is not frequently inspected, it will cause catastrophic events with financial as well as human life losses. 
Methods employed for pipeline damage detections are fibre optic sensor based method, acoustic emission method, eddy current method, etc.

Electromechanical impedance technique is one of the non-destructive evaluation techniques of structural health monitoring using smart material PZT (lead zirconate titanate) which is light in weight, small in size and available in various shapes. PZT can act as sensor as well as actuator. The basic principle of EMI technique is that change in stiffness, mass or damping of the structure causes change in mechanical impedance of structure which is equal to electrical impedance of PZT. Admittance vs frequency graph is obtained through elctromechanical coupling of PZT with structure. Response for healthy state is called healthy signatures. Change in stiffness causes change in electrical impedance of PZT in damaged and intact state.

The conventional EMI technique has some drawbacks such as direct bonding of small brittle PZT patch over structure is difficult due to geometry of structure, structure under impact forces, inaccessible structure locations; high temperature structures etc. To eliminate aforementioned drawbacks of conventional EMI technique new method is introduced. EMI technique using advanced PZT is made by introducing one of the metal connector in between structure and PZT. It eliminates direct bonding of PZT to the structure.

The piezo impedance based method has been effectively monitoring a number of steel structures. Bhalla and Naskar (2014) recently reported experimental study on Metal wire based variant of EMI technique for steel structures. The main objective was to monitor the 2D plate and studied the some parameters of metal wire based EMI technique [1]. Park et al. (2000) carried out experimental study on impedance based health monitoring technique for massive structures and high temperature structures using commercial PZT. They showed that method can be successfully applied for massive structures [2]. Du et al. (2013) presented a feasibility study on the crack detection and severity monitoring of pipelines using PZT transducers [3]. Na and Lee (2012) presented a technique for selecting Resonance frequency range utilized for damage detection of composite structures. Further they worked on Steel wire electromechanical impedance method using a piezoelectric material for composite structures with complex surfaces [4]. Na and Lee (2013) carried out health monitoring of composite and complex structure using steel wire electromechanical impedance method using piezoelectric material [5]. Bhall S. (2004) presented a mechanical impedance approach for structural identification health monitoring and non destructive evaluation using piezo impedance transducer [6]. Farrar C. R. and Worden K. (2007) introduced to structural health monitoring [7]. Lalande et al. (1996) extended high frequency impedance technique for complex precision parts [8].

In the present investigative study, experimental setups are developed to acquire structural response from the advanced piezoelectric transducer (PZT) patches bonded through the metal connector and to predict the damages by using high frequency technique. The structural damage is identified by studying the responses for healthy state and damaged state and comparing them using EMI technique. Firstly experiment was performed to detect locations of damages and severity of damages. The technique fur- 
ther extended to study effect of temperature variation along with detecting progressive damage. In last section the study extended to detect locations of damages and severity of damages. The results of all the experiments showed the best applicability of structural health monitoring using high frequency technique of PZT patches for steel curved surfaces. The study is performed to understand effect of temperature variation along with detecting progressive damage of pipe specimen.

\subsection{Damage Quantification}

The damage is materialized by Root Mean Square Index (RMSD). The healthy conductance signature for the PZT patches instrumented at ends of metal connector is obtained. Artificial damage is introduced in the specimen. At damaged state conductance signature is again recorded. Damage index is given by

$$
M=\sqrt{\frac{\sum\left(G_{2}-G_{1}\right)^{2}}{\sum G_{1}^{2}}}
$$

where

$$
\begin{aligned}
& M=\text { RMSD } \% \\
& G_{1}=\text { Base line conductance signature. } \\
& G_{2}=\text { Conductance signature obtained after period of time. }
\end{aligned}
$$

\section{Fabrications of Advanced PZT}

The present advanced PZT is made by using connector, aluminium foil having $200 \mathrm{~mm}$ length, $10 \mathrm{~mm}$ width and $2 \mathrm{~mm}$ thickness. At one of the ends of foil PZT patch was attached using Araldite as shown in Figure 1. The PZT patch used is manufactured at the Central Electronics Limited, Sahibabad of high frequency range of grade PZT-5H having size $10 \mathrm{~mm} \times 10 \mathrm{~mm} \times 0.2 \mathrm{~mm}$ as shown in Figure 2(a). The wire used is coaxial head wire to reduce losses of signatures. LCR meter E4980A as shown in Figure 2(b) of

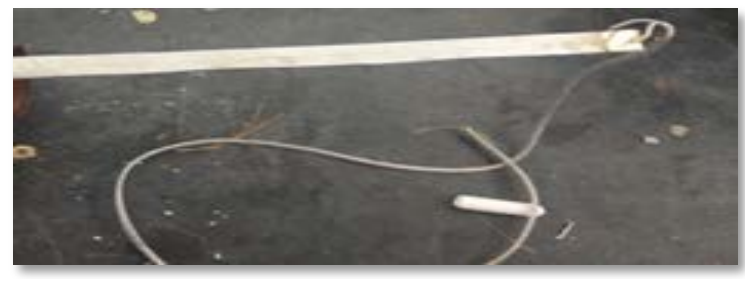

Figure 1. Aluminium foil connected PZT.

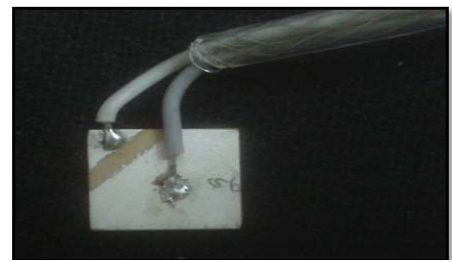

(a)

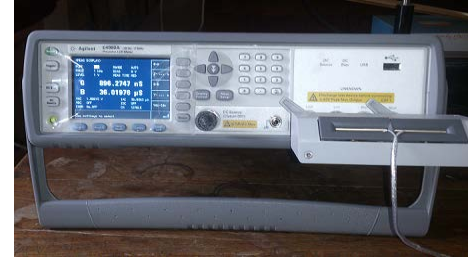

(b)

Figure 2. (a) PZT 5-H grade sample, (b) LCR meter. 
frequency range of $20 \mathrm{~Hz}$ to $2 \mathrm{MHz}$ was used for obtaining and analyzing the responses of advanced PZT patches for damages of host structure at any stage. VEE Pro program is employed to acquire the data from LCR meter through USB cable.

\section{Experimental Investigation}

\subsection{General}

In this paper, two studies are performed for the purpose of different parametric studies

1) To detect locations of damages and severity of damages of pipe specimen.

2) To study effect of temperature variation along with detecting progressive damage of pipe specimen.

In this investigative study, the pipe specimen for the experiments is used as follows.

\subsection{Experiment Performed to Detect Locations of Damages and Severity of Damages}

In this experiment pipe used is of dimensions, length of $1000 \mathrm{~mm}$, diameter of $25 \mathrm{~mm}$ and $1 \mathrm{~mm}$ thickness is instrumented with aluminium foil connected PZT at the right end of pipe as shown in Figure 3. Enlarged view of advanced PZT is shown in Figure 5(a). A base line signature (conductance) was obtained for intact structure. For location study first damage was introduced at $800 \mathrm{~mm}$ from foil. Response is recorded for the damage. After that second damage was introduced at $350 \mathrm{~mm}$ from foil as shown in Figure 4. Again response was recorded. Comparison of both records gives effect of location on performance of advanced piezo impedance technique. For the severity of damage study the existing damages were increased one by one, and response was obtained. For e.g. the width of damage was increased as shown in Figure 5(b).

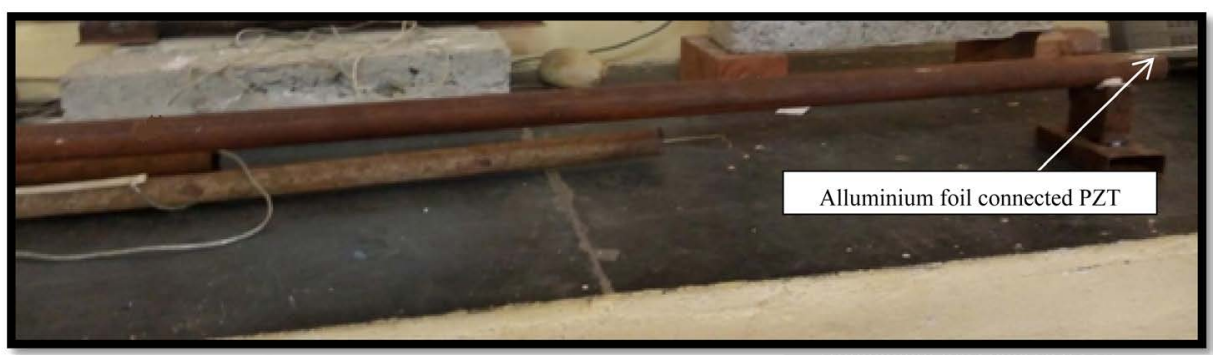

Figure 3. Experimental setup of pipe specimen instrumented with aluminium foil connected PZT.

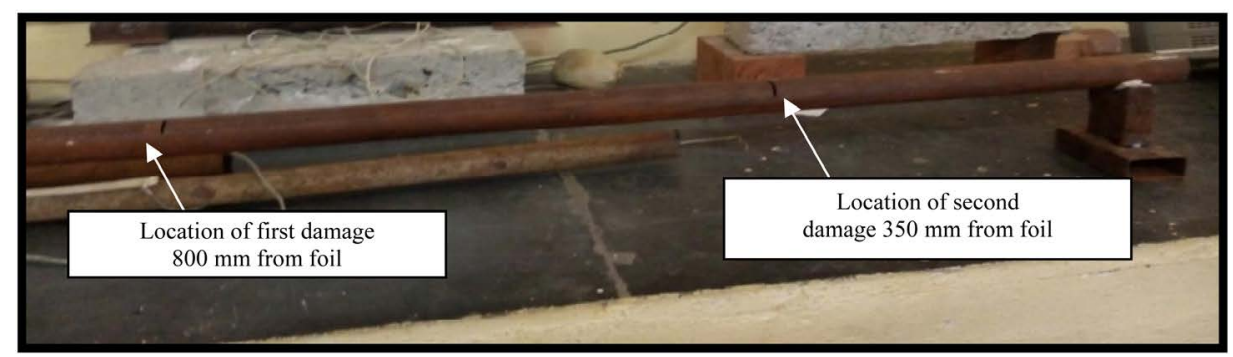

Figure 4. Presentation of various damage locations. 


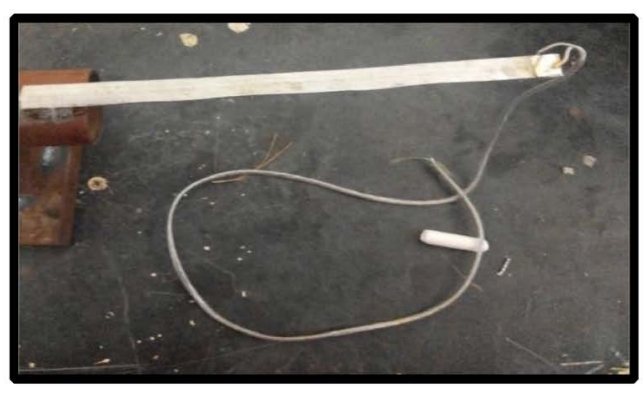

(a)

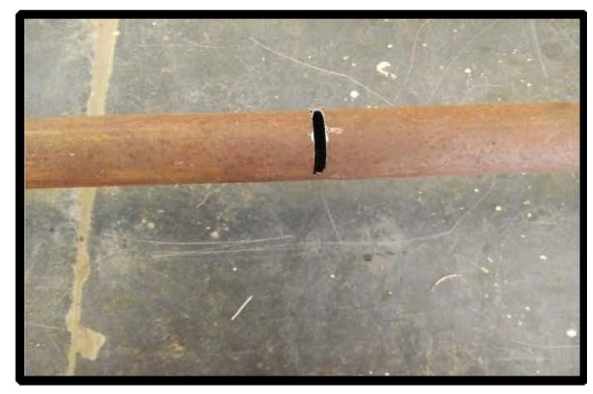

(b)

Figure 5. (a) Arrangement of aluminium foil with pipe, (b) enlarged view of increased damage.

\subsection{Experiment Performed to Study Effect of Temperature Variation along with Detecting Progressive Damage of Pipe Specimen Subjected to High Temperature}

This case study was effected for detection of progressive damage of the structure which is subjected to high temperature. For the experiment the pipe specimen used is of length $500 \mathrm{~mm}$, diameter of $25 \mathrm{~mm}$ and $1 \mathrm{~mm}$ thickness and temperature was measured by using temperature indicator as shown in Figure 6. Pipe was instrumented with aluminium foil connected PZT at the right end using adhesive Bond Tite as shown in Figure 7. To study the mentioned parameter pipe was heated to different temperature levels using electric heater as shown in Figure 8. Pipe temperature was raised to $40^{\circ} \mathrm{C}$ and the reading was taken i.e. healthy signature. Again the temperature of pipe was raised to $60^{\circ} \mathrm{C}$ and corresponding conductance and susceptance signatures were taken further temperature raised up to $80^{\circ} \mathrm{C}$ and reading was recorded. Finally temperature raised to $100^{\circ} \mathrm{C}$ and readings was recorded. The readings of different temperature levels were compared. The damages were introduced at three different locations one by one when pipe was reached to steady constant temperature $100^{\circ} \mathrm{C}$ as shown in Figure 9. Damage 1 was introduced at $450 \mathrm{~mm}$ from the foil and corresponding signature were noted and same were compared with healthy signatures. The damage 2 was introduced at $250 \mathrm{~mm}$ from foil and readings are compared with healthy readings and also with previous damage (1) readings. The damage 3 was introduced at $150 \mathrm{~mm}$ from foil and followed same procedure as mentioned above. The RMSD indices graph were plotted for different damage levels.

\section{Results and Discussions}

\subsection{Result of Experiment Performed to Detect Locations of Damages and Severity of Damages}

The PZT patch connected to pipe through aluminum foil was subjected to the frequency range of 100-250 kHz. The conductance and susceptance graphs are plotted for healthy state. For the study of locations of damages, the conductance readings are acquired for first damage and compared with the healthy signatures as shown in Figure 10. The conductance graph is plotted for the second damage along with comparison with healthy conductance signature as shown in Figure 11. Corresponding damage in- 


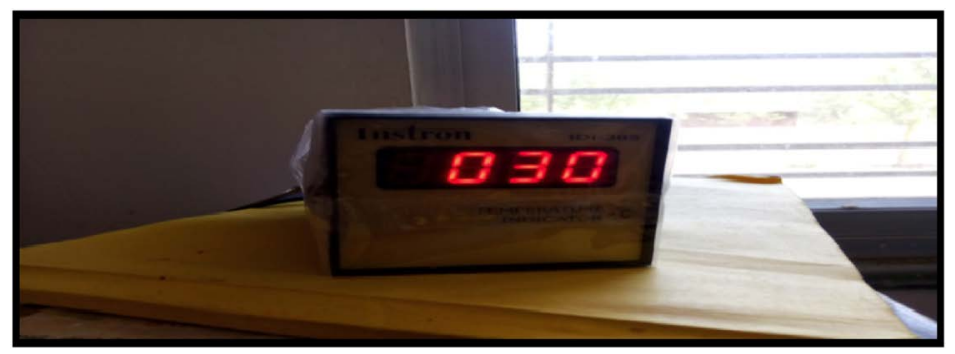

Figure 6. Temperature indicator.

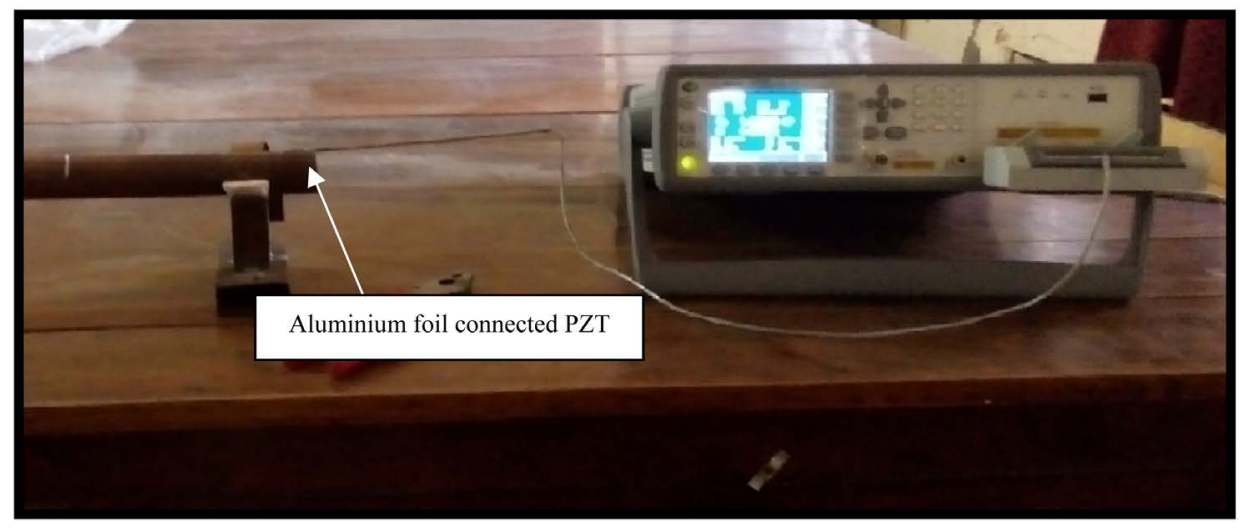

Figure 7. Right end of pipe.

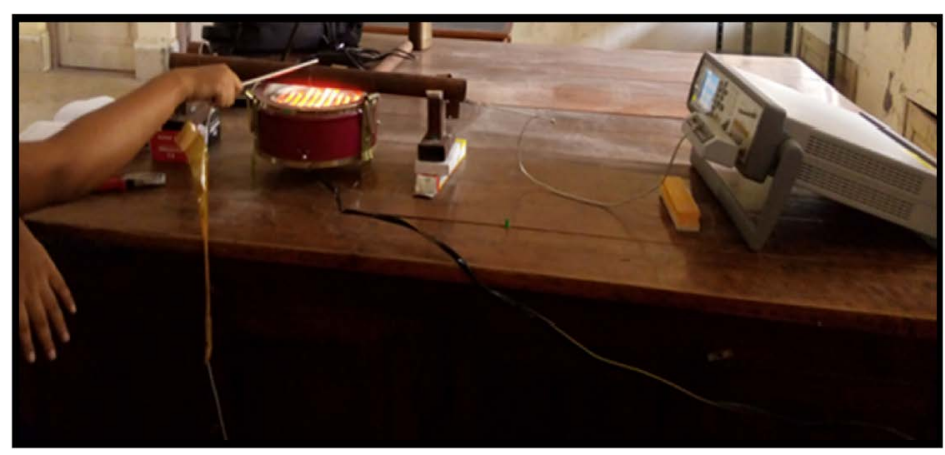

Figure 8. Experimental setup.

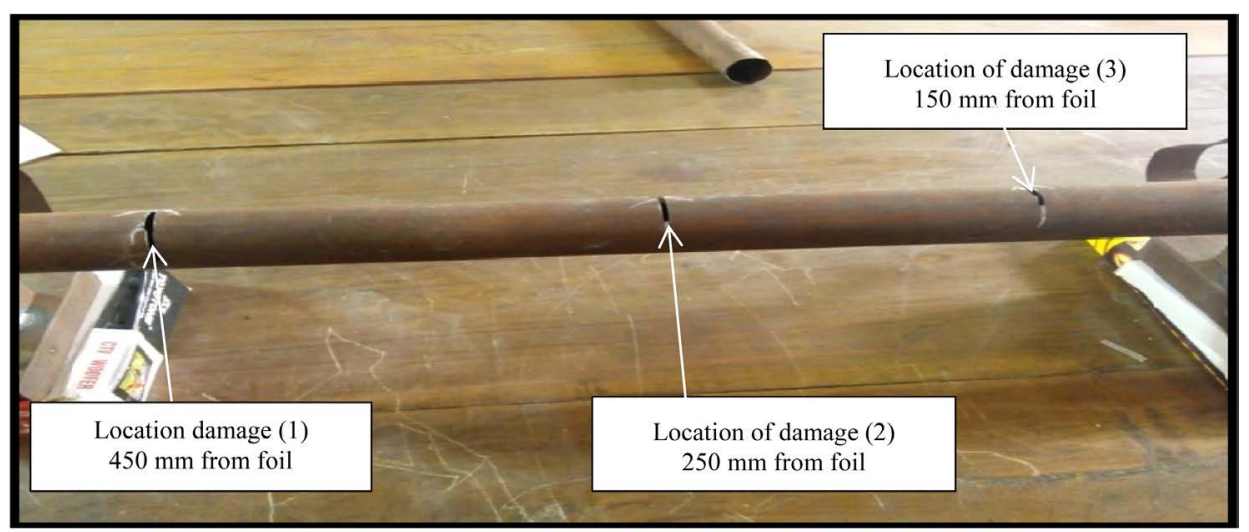

Figure 9. Presentation of location of damages. 


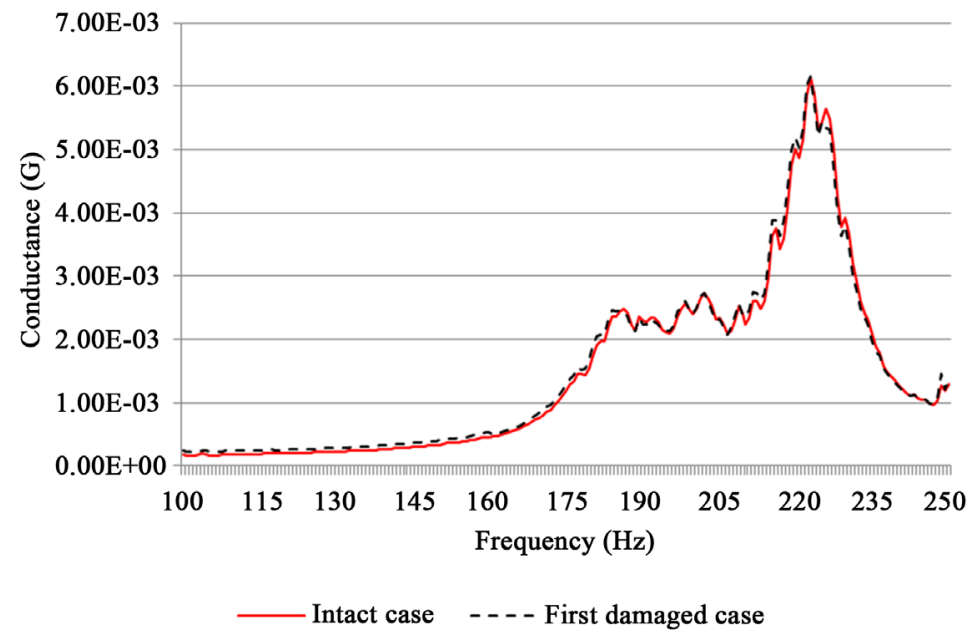

Figure 10. Superimposed conductance signature of intact and first damaged case.

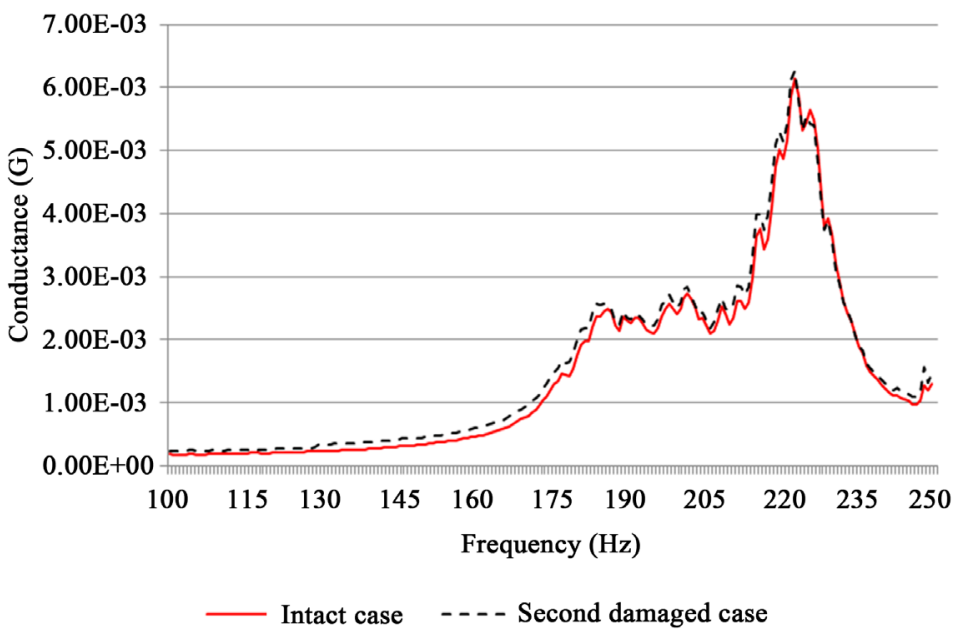

Figure 11. Superimposed conductance signature of intact and second damaged case.

dex for first damage and second is plotted as shown in Figure 12. To study severity of damage, the width of second damage was increased which is near to the foil and superimposed graphs of conductance vs frequency are shown in Figure 13. The width of first damage was increased and superimposed graphs of conductance vs frequency were plotted as shown in Figure 14. The corresponding damage index is shown in RMSD plot (Figure 15).

It is observed from the graph that, for the first damage which is at $800 \mathrm{~mm}$ away from the foil is shows less shift in conductance signature for damaged state than the second damage conductance signature which is nearer to the foil at $350 \mathrm{~mm}$ from foil. From the RMSD graph it is clearly seen that the first damage is away from the foil than the second damage.

It is observed from the graphs that, first damage was away from the foil and second damage was nearer to foil. The damage which was nearer to foil i.e. second damage was firstly increased and RMSD index was calculated. After that the first damage was in- 


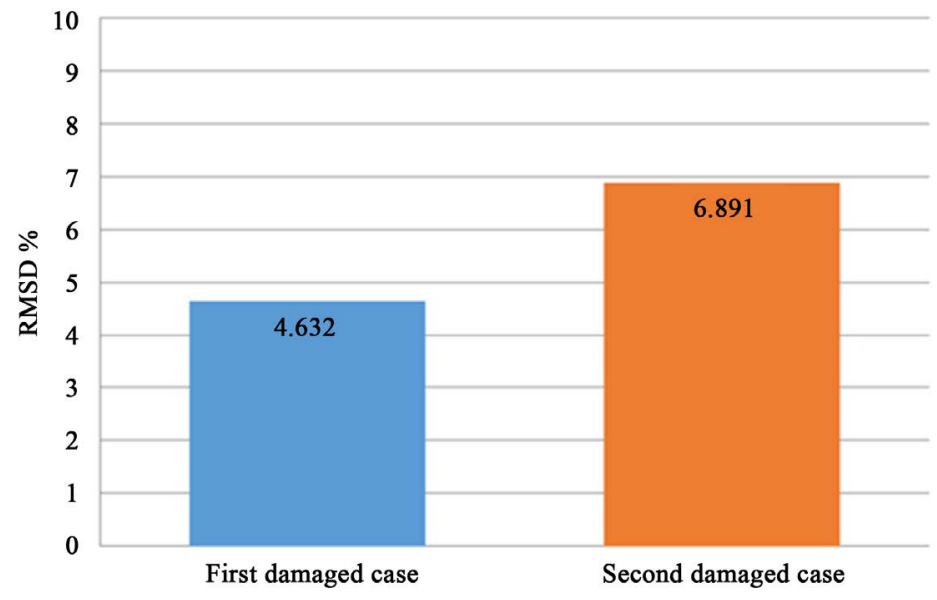

Figure 12. RMSD plot for location study.

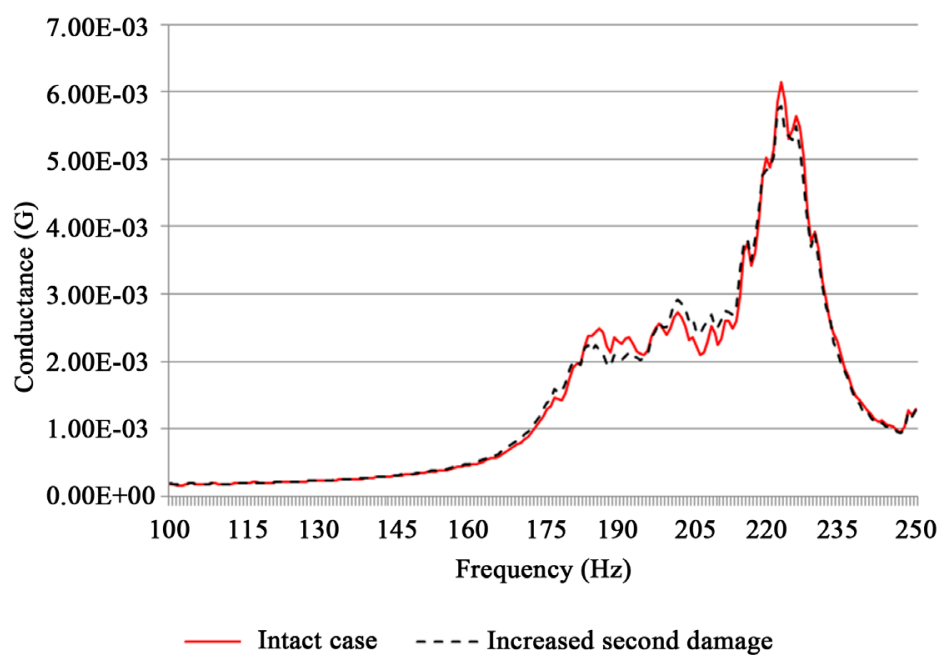

Figure 13. Superimposed conductance signature of intact and second damage increased case.

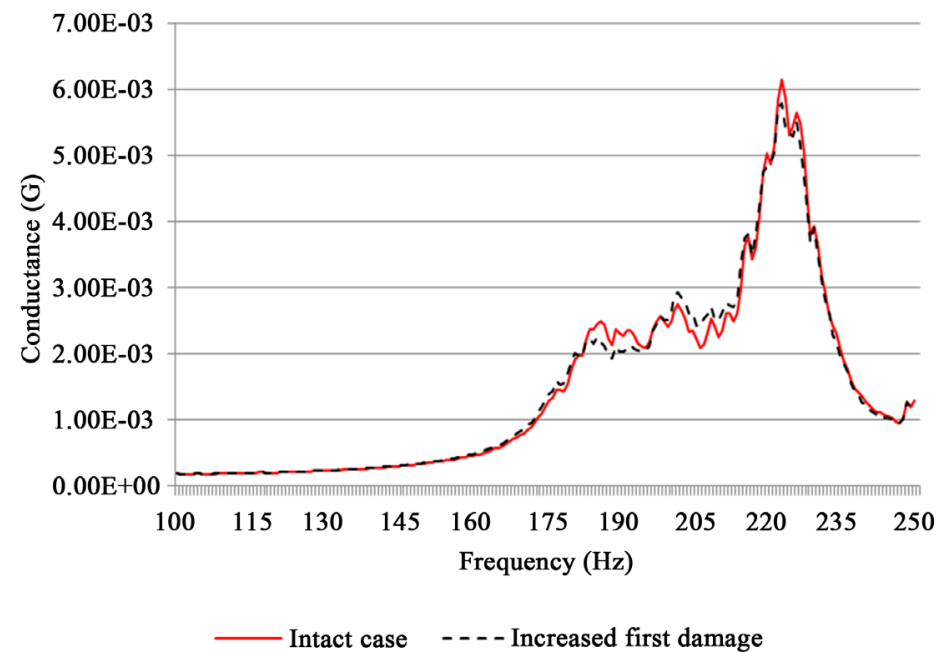

Figure 14. Superimposed conductance signature of intact and first damage increased case. 


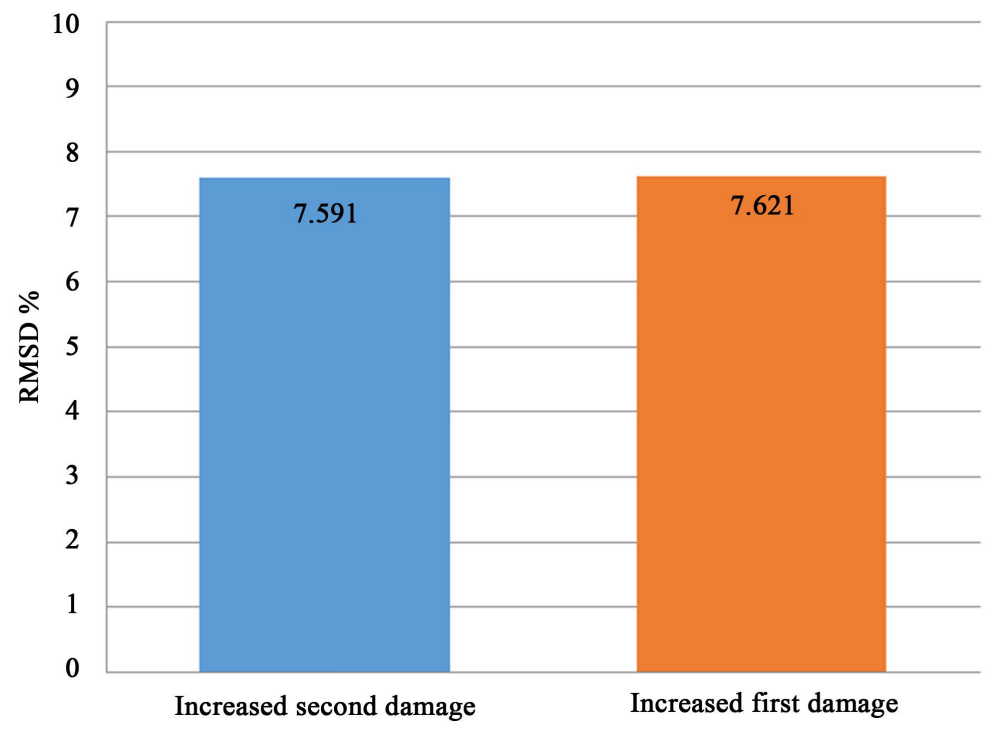

Figure 15. RMSD plot for severity study.

creased which was away from the foil and again RMSD index was calculated. The RMSD index for both increased damage are nearly same.

\subsection{Results of Experiment Performed on High Temperature Curved Surface Subjected Progressive Damage}

The PZT patch attached to the pipe was subjected to frequency range $100-250 \mathrm{kHz}$ through the aluminium foil in this range the superimposed conductance and susceptance graphs are drawn for each temperature level for $40^{\circ} \mathrm{C}, 60^{\circ} \mathrm{C}, 80^{\circ} \mathrm{C}$ and $100^{\circ} \mathrm{C}$ as shown in Figure 16 and Figure 17 respectively. To study detection of progressive damage the damages 1,2 and 3 are introduced one by one at $100^{\circ} \mathrm{C}$ temperature using steel cutter and compared with healthy signature at $100^{\circ} \mathrm{C}$. The conductance and susceptance signatures of damage 1 which is at $450 \mathrm{~mm}$ from the foil are compared with healthy conductance and susceptance signatures as shown in Figure 18 and Figure 19 respectively. The conductance and susceptance signatures of damage $2(250 \mathrm{~mm}$ away from foil) and damage 1 are compared with healthy conductance and susceptance graph as shown in Figure 20 and Figure 21. Lastly, the superimposed signatures of damage 3 (at $150 \mathrm{~mm}$ from foil), damage 2, damage 1 and healthy signatures are plotted as shown in Figure 22 and Figure 23. RMSD plot for comparison of three damages is plotted as shown in Figure 24.

It is observed from the graphs of conductance, susceptance and admittance for different temperature levels does not shows much change for different temperature levels. Hence it is concluded that there is less variation in stiffness of pipe less variation in curve.

It is observed from the graphs of conductance and susceptance for each damage as the distance of damage from foil is increased shift in curve is less than the damage which is nearer to the foil and also calculated RMSD for first damage is less than second 


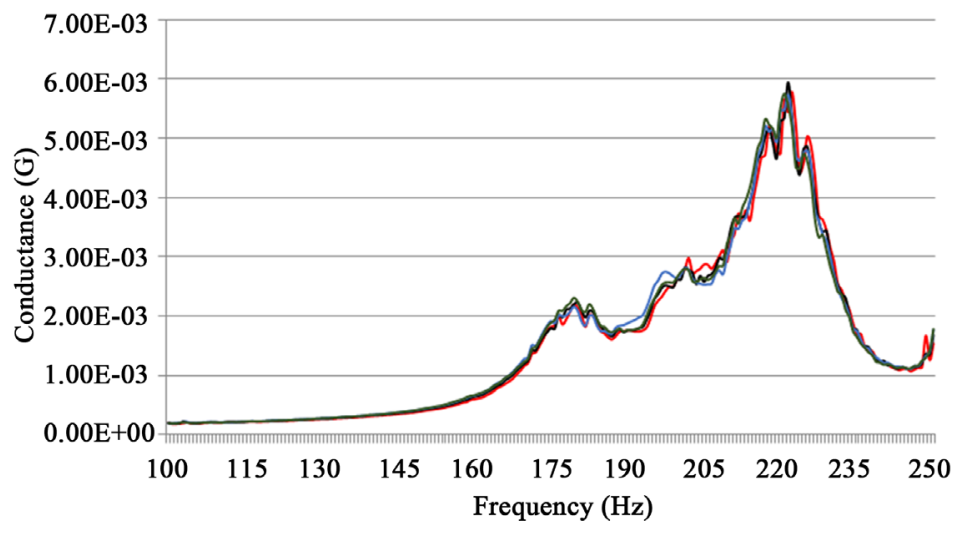

- Reading at $40^{\circ} \mathrm{C} \longrightarrow$ Reading at $60^{\circ} \mathrm{C}$

- Reading at $80^{\circ} \mathrm{C} \longrightarrow$ Reading at $100^{\circ} \mathrm{C}$

Figure 16. Superimposed conductance signature for different temperature levels.

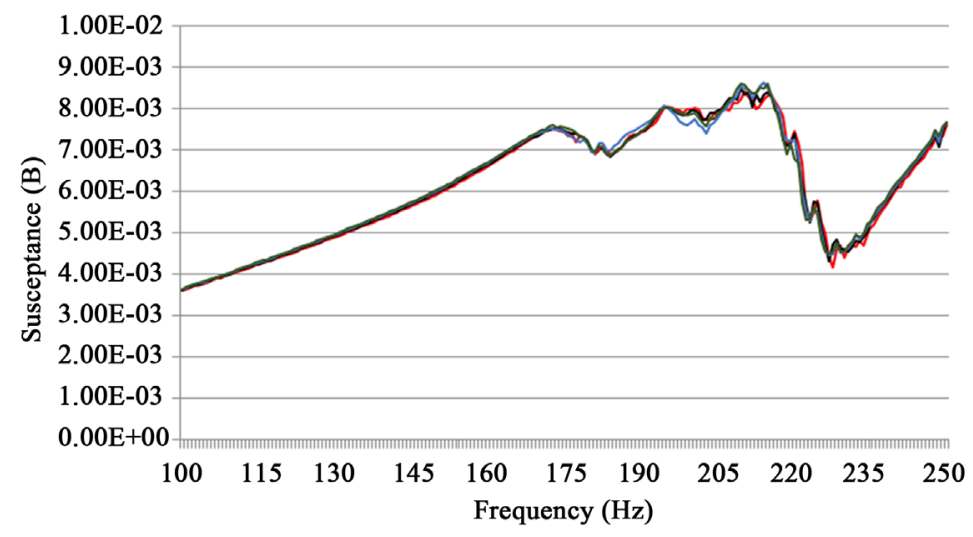

- Reading at $40^{\circ} \mathrm{C}$ - Reading at $60^{\circ} \mathrm{C}$

- Reading at $80^{\circ} \mathrm{C}$ - Reading at $100^{\circ} \mathrm{C}$

Figure 17. Superimposed susceptance signature for different temperature levels.

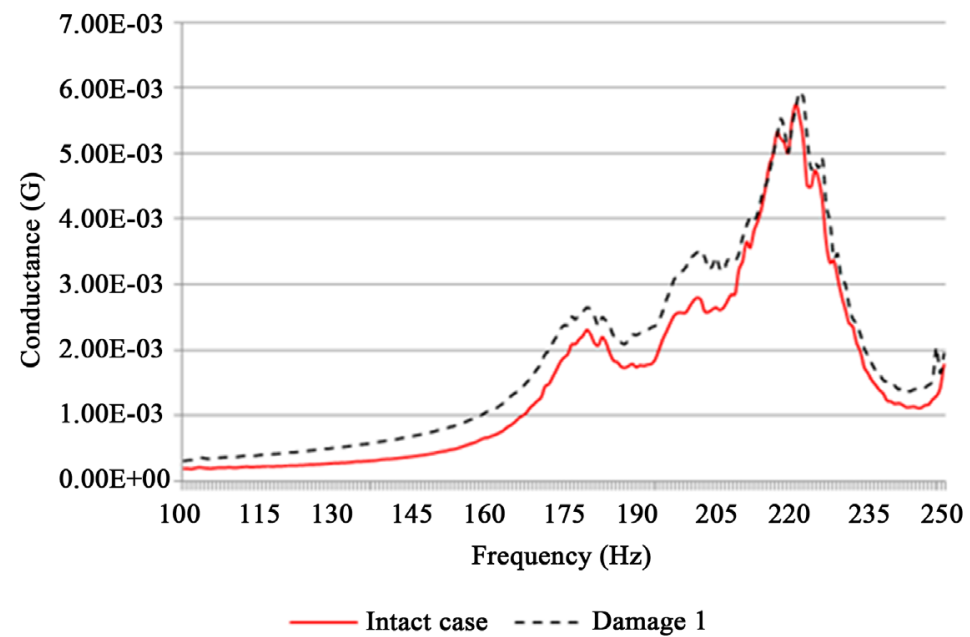

Figure 18. Superimposed conductance signature for intact and damage (1) case. 


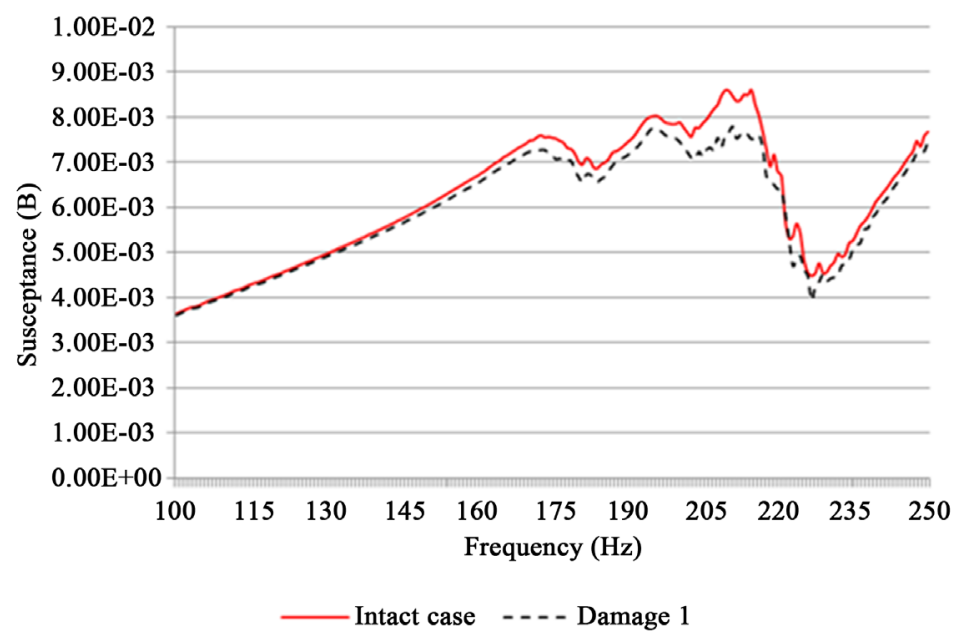

Figure 19. Superimposed susceptance signature for intact and damage (1) case.

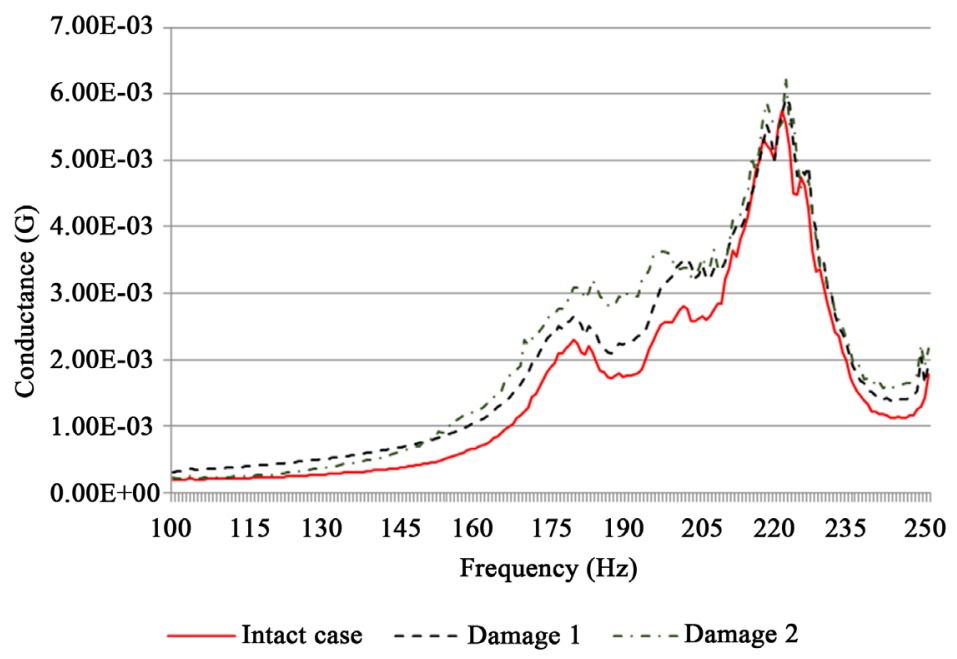

Figure 20. Superimposed conductance signature for intact and damage $(1+2)$ case.

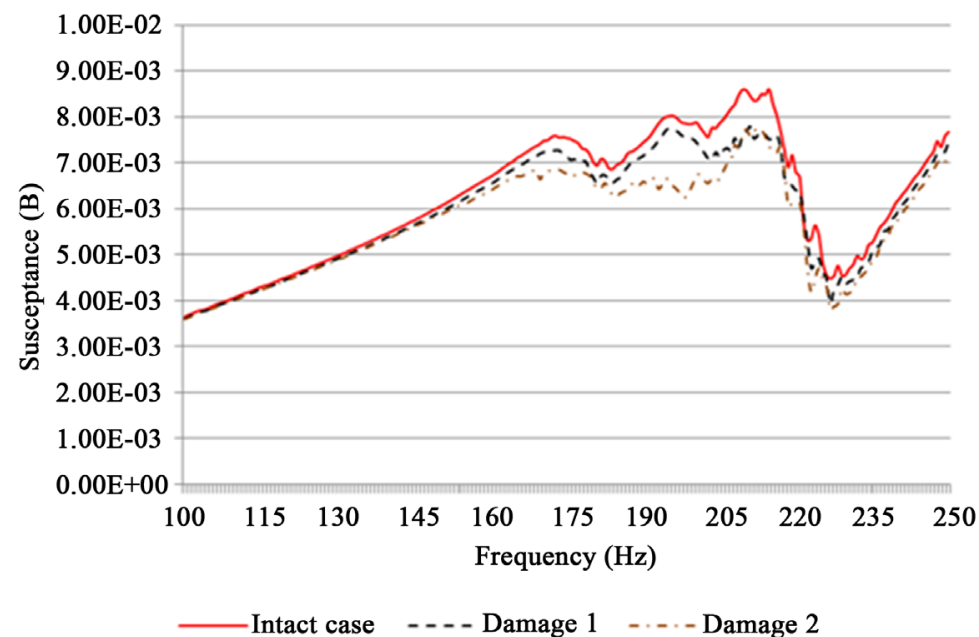

Figure 21. Superimposed susceptance signature for intact and damage $(1+2)$ case. 


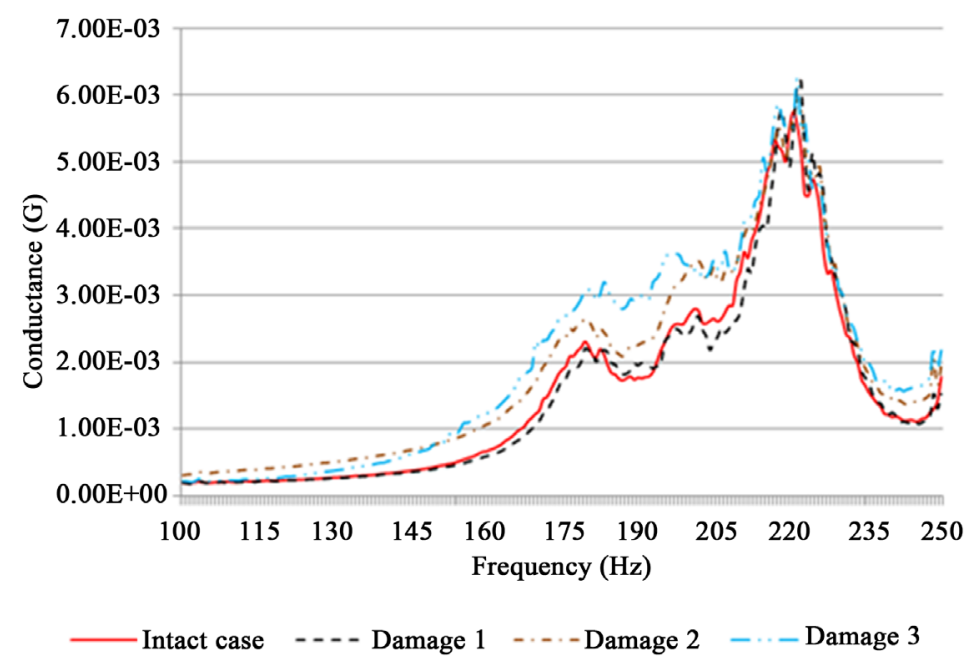

Figure 22. Superimposed conductance signature for intact and damage $(1+2+3)$ case.

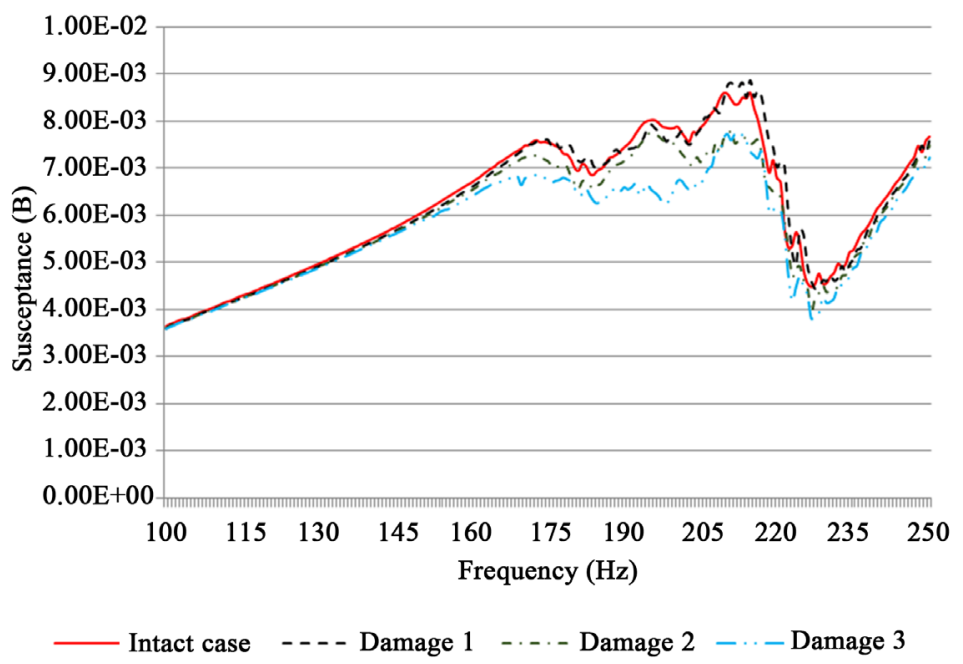

Figure 23. Superimposed susceptance signature for intact and damage $(1+2+3)$ case.

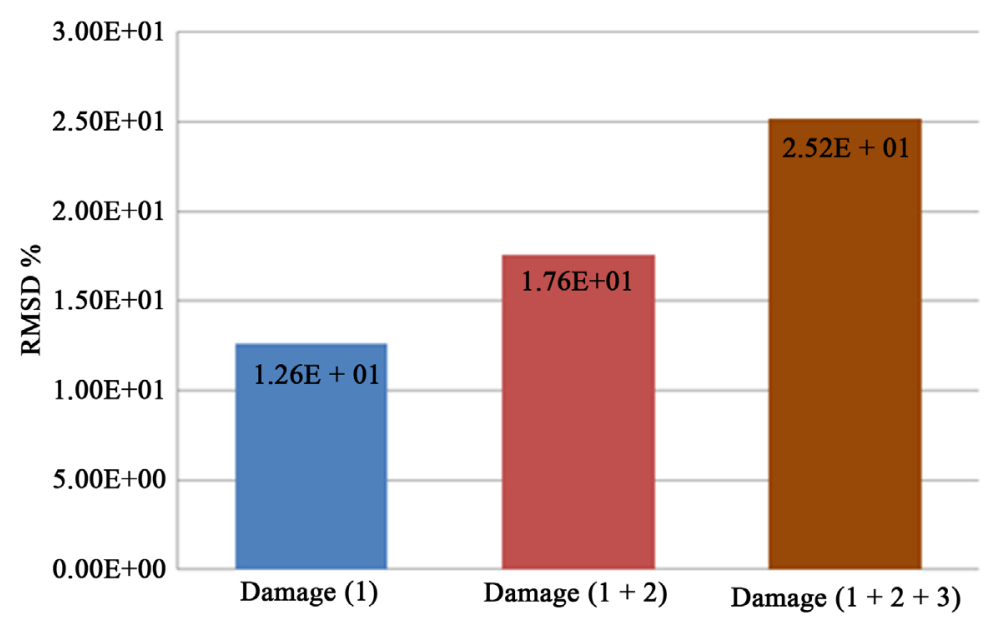

Figure 24. RMSD graph for comparison of three damages. 
and third damage which are relatively nearer to the foil and RMSD for second damage is less than the third damage which is more nearer than second damage.

It is observed from the above RMSD graph, RMSD for the undamaged temperature variation is very less compared to RMSD for damaged state as shown in Figure 25. Also it is observed in the conductance signature for the temperature variation shifting of curves is very less and for the damaged state shifting of curve is very high as visible in Figure 26.

\section{Conclusions}

The fundamental aim of this investigation is to study feasibility and effectiveness of advanced piezo impedance EMI technique for the monitoring of curved surfaces. The basic advantage of the method is ease of application to complex surfaces and also applica-

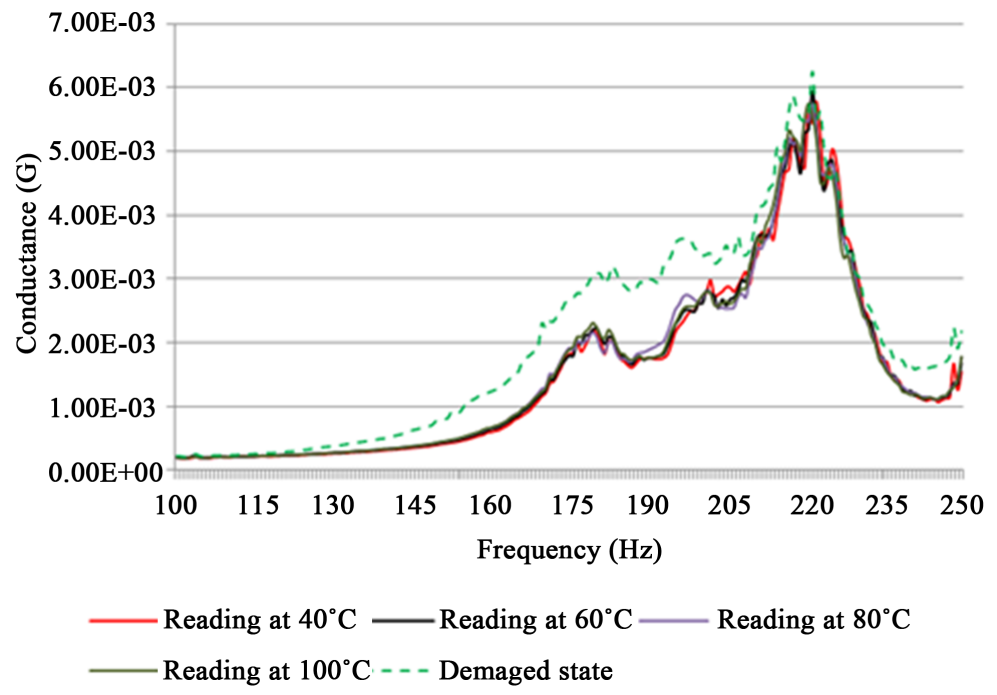

Figure 25. Superimposed conductance signature for healthy and damaged state.

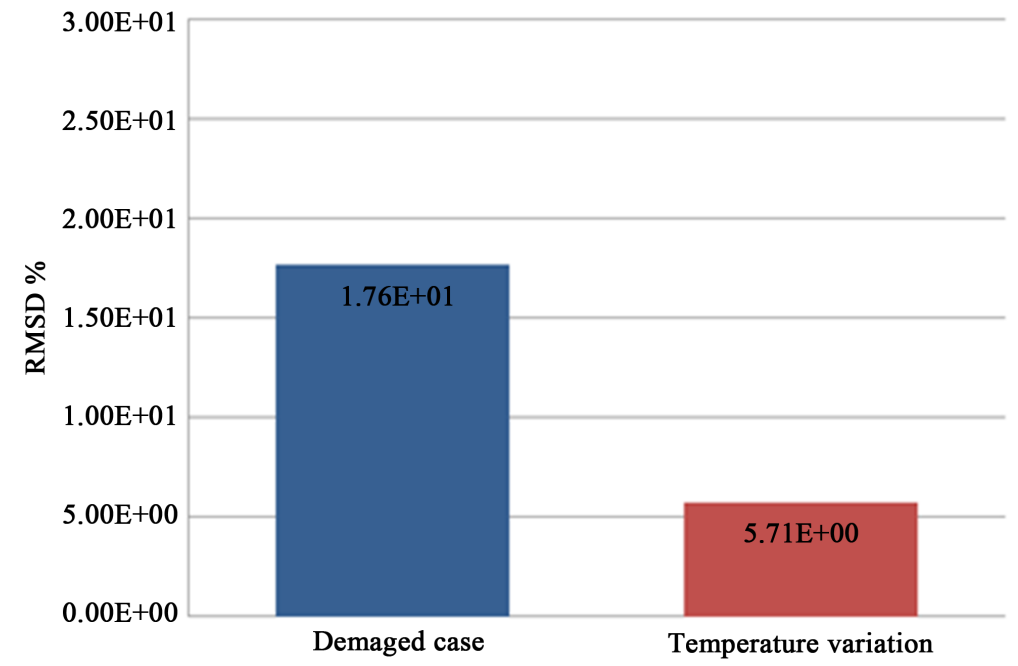

Figure 26. RMSD comparison graph for temperature variation and damaged state. 
tion to situation where surface is at temperature higher than Curie temperature. The present work explored these advantages and established effectiveness of the technique. Following conclusions are drawn from the various tests performed on flat and curved surfaced beams.

- It can be concluded from damage detection study, that damage can be identified by vertical and lateral shifting of peaks and by alteration of conductance values for healthy and different damage conditions.

- It can be concluded that advanced piezo impedance is location sensitive as it shows higher damage sensitivity when advanced PZT is positioned near the damage.

- Root mean square deviation is found to be effective method for the damage quantification.

- The technique is severity sensitive as the severity increases damage index also increases.

- The temperature variation indicates changes in stiffness and damping characteristics of structure which is effectively detected by advanced piezo impedance transducer.

- For the given temperature range the Metal Connector Based (MCB) EMI technique was found to be effective.

- It can be concluded that metal connector PZT are also location sensitive even for structures subjected to different temperature levels.

- Progressive damage of heated pipes was effectively identified by the advanced piezo impedance transducers. It can also be concluded that the monitoring of progressive damage is possible using the presented advanced piezo impedance transducer.

\section{References}

[1] Bhalla, S. and Naskar, S. (2014) Experimental Investigation of Metal Wire Based Variant of EMI Technique for Steel Structures and Systems. Proceedings of 7 th ISSS Conference on Smart Materials Structures and Systems, Banalore, 8-11 July 2014, Paper No. 1569922. http://web.iitd.ac.in/ sbhalla/ISSS649.pdf

[2] Park, G., Cudney, H. and Inman, D.J. (2000) Impedance-Based Health Monitoring of Civil Structural Components. Journal of Infrastructure Systems, ASCE, 6, 153-160. http://dx.doi.org/10.1061/(ASCE)1076-0342(2000)6:4(153)

[3] Du, G.F., Kong, Q.Z., Lai, T. and Song, G.B. (2013) Feasibility Study On Crack Detection of Pipelines Using Piezoceramic Transducers. International Journal of Distributed Sensor Networks, 9, 1-7. http://dx.doi.org/10.1155/2013/631715

[4] Na, S. and Lee, H.K. (2012) Resonant Frequency Range Utilized Electro-Mechanical Impedance Method for Damage Detection Performance on Composite Structures. Composite Structure, 94, 2383-2389. http://dx.doi.org/10.1016/j.compstruct.2012.02.022

[5] Na, S. and Lee, H.K. (2013) Steel Wire Electromechanical Impedance Method Using a Piezoelectric Material for Composite Structures with Complex Surfaces. Composite Structures, 98, 79-84. http://dx.doi.org/10.1016/j.compstruct.2012.10.046

[6] Bhall, S. (2004) A Mechanical Impedance Approach for Structural Identification, Health Monitoring and Non-Destructive Evaluation Using Piezo-Impedance Transducer. Thesis, Indian Institute of Technology, Delhi.

[7] Farrar, C.R. and Worden, K. (2007) An Introduction to Structural Health Monitoring. Phi- 
losophical Transactions of the Royal Society A, 365, 303-315. http://dx.doi.org/10.1098/rsta.2006.1928

[8] Lalande, F., Childs, B., Choudhary, Z. and Rogers, C.A. (1996) High-Frequency Impedance Analysis for NDE of Complex Precision Parts. Proceedings, SPIE Conference on Smart Structures and Materials, San Diego, 26-29 February, 237-245.

Submit or recommend next manuscript to SCIRP and we will provide best service for you:

Accepting pre-submission inquiries through Email, Facebook, LinkedIn, Twitter, etc. A wide selection of journals (inclusive of 9 subjects, more than 200 journals)

Providing 24-hour high-quality service

User-friendly online submission system

Fair and swift peer-review system

Efficient typesetting and proofreading procedure

Display of the result of downloads and visits, as well as the number of cited articles

Maximum dissemination of your research work

Submit your manuscript at: http://papersubmission.scirp.org/

Or contact ojce@scirp.org 